\title{
Keratin-based particles for protection and restoration of hair properties
}

\author{
A. Tinoco*,a , J. Gonçalves*,a , C. Silva*, A. Loureiro*, A. C. Gomes ${ }^{\dagger}$, A. Cavaco-Paulo* iD and A. Ribeiro* \\ ${ }^{*}$ CEB-Centre of Biological Engineering, University of Minho, Campus of Gualtar, 4710-057 Braga, Portugal and ${ }^{\dagger}$ Centre of Molecular and \\ Environmental Biology (CBMA), Department of Biology, University of Minho, Campus of Gualtar, 4710-057 Braga, Portugal
}

Received 5 April 2018, Accepted 23 July 2018

Keywords: emulsion, formulation/stability, hair treatment, keratin-based particles, overbleached hair, virgin hair

\begin{abstract}
OBJECTIVE: Human hair is an element with unquestionable relevance in society both for women and men. Therefore, it is of great importance to develop new cosmetic products for hair care capable to restore and improve hair's characteristics. Here, we explore the potential of keratin-based particles in the protection and recovery of hair mechanical properties and thermal stability.

METHODS: Keratin-based particles were obtained by high pressure homogenization (HPH) using keratin and silk fibroin. The particles were characterized regarding size, superficial charge and polydispersity index. Their safety to cells was assessed using human skin keratinocytes. Virgin and overbleached Asian hair were treated with eight keratin-based formulations. The effect of particles on hair's mechanical properties was evaluated in terms of stiffness and tensile strength. The impact of treatments in hair thermal performance was studied using differential scanning calorimetry (DSC).

RESULTS: Keratin-based particles were capable to recover and/or improve the mechanical properties of virgin and overbleached hair. Virgin hair treated with $\mathrm{K}_{80} \mathrm{SF}_{20} \mathrm{P}$ particles presented an improvement in the mechanical properties of around $40 \%$. An increase in keratin $\alpha$-helix denaturation enthalpy and in surface smoothness for both types of hair was also verified after treatment. These particles demonstrated stability over time and proved to be safe when tested in human keratinocytes.

CONCLUSION: The keratin-based particles here presented have the potential to be incorporated in the development of new and effective hair care cosmetic formulations.
\end{abstract}

\section{Résumé}

OBJECTIF: Les cheveux sont un élément avec une importance incontestable dans la société pour les femmes et les hommes. Par conséquent, il est primordial de développer de nouveaux produits cosmétiques pour les soins capillaires capables de restaurer et d'améliorer les caractéristiques des cheveux. Ici, nous explorons le potentiel des particules à base de kératine dans la protection, la

Correspondence: Artur Ribeiro and Artur Cavaco-Paulo, CEB-Centre of Biological Engineering, University of Minho, Campus of Gualtar, 4710057 Braga, Portugal. Tel.: (+351) 253601 968; fax: (+351) 253 604 429; e-mail: arturibeiro@ceb.uminho.pt (AR); Tel.: (+351) 253 604 409; fax: (+351) 253604 429; e-mail: artur@deb.uminho.pt (ACP).

${ }^{\mathrm{a}}$ These authors have equally contributed. récupération des propriétés mécaniques et de la stabilité thermique des cheveux.

MÉTHODES: Les particules à base de kératine ont été obtenues par homogénéisation à haute pression (HPS) utilisant la kératine et la fibrö̈ne de soie. Les particules ont été caractérisées par la taille, la charge superficielle et l'indice de polydispersité. Leurs toxicités ont été évaluées en utilisant des kératinocytes de peau humaine. Des cheveux asiatiques vierges et décolorés ont été traités avec huit formulations à base de kératine. L'effet des particules sur les propriétés mécaniques des cheveux a été évalué en termes de rigidité et résistance à la traction. L'impact des traitements dans la performance thermique des cheveux a été étudié utilisant l'analyse calorimétrique différentielle à balayage (DSC).

RÉSULTATS: Les particules à base de kératine étaient capables de récupérer et/ou d'améliorer les propriétés mécaniques des cheveux vierges et décolorés. Les cheveux vierges, traité avec des particules $\mathrm{K}_{80} \mathrm{SF}_{20} \mathrm{P}$ ont présenté une amélioration des propriétés mécaniques d'environ $40 \%$. Une augmentation de l'enthalpie de dénaturation de l' $\alpha$-hélice de kératine et de la rugosité de surface a été vérifiée également pour les deux types de cheveux après le traitement. Ces particules ont démontré leur stabilité dans le temps et avéré sûres d'après le tests sur keratinocytes humains.

CONCLUSION: Les particules à base de kératine ici présentées ont le potentiel d'être incorporé dans le développement de formulations cosmétiques nouvelles et efficaces pour les soins capillaires.

\section{Introduction}

Hair is an important component of the body image with great psychological importance for both men and women, which we can change and manipulate according to culture and fashion [1]. Nevertheless, successful cosmetic alteration of hair, such as colouring and straightening, usually require harsh chemical processes altering the normal structure of the hair shaft. Bleaching is a chemical process commonly used in hair coloration to eliminate or lighten hair natural tone and prepare the hair fibre for dyeing [2]. This process uses strong oxidative agents, which destroy the disulphide bonds within the keratin resulting in a decrease in hair fibres' properties [2]. Around $80 \%$ of human hair is formed by $\alpha$-keratin protein located into the cortex, that is responsible for the hair strength, flexibility, durability, and functionality [3]. After bleaching, the hair may appear cloudy, dry, rough, fragile and dull, presenting alterations in its mechanical and surface properties [3]. 


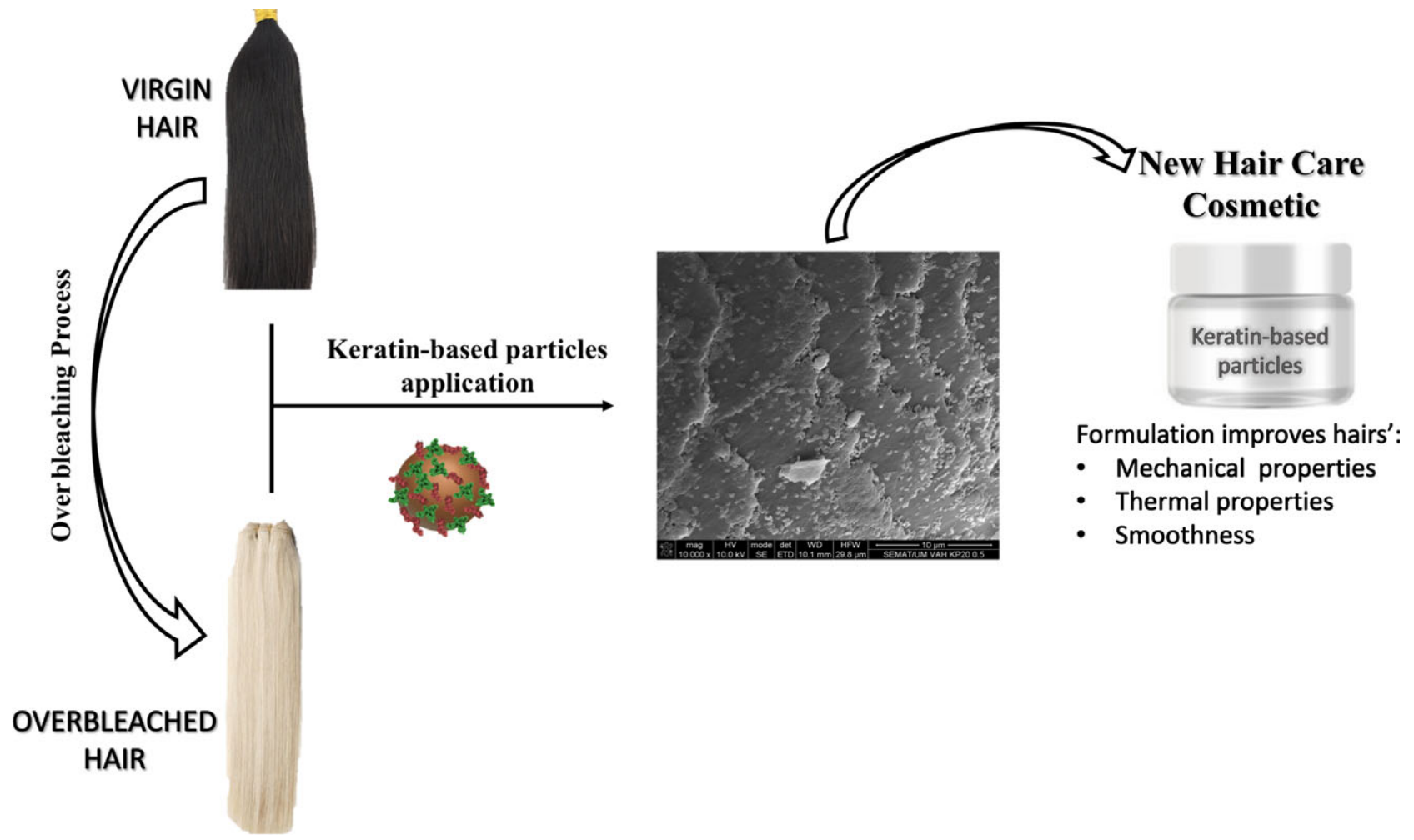

Figure 1 Scheme showing the fundamental concept of the described research study. Application of keratin-based particles as innovative hair care cosmetic formulations to improve the smoothness, the mechanical properties and the thermal stability of virgin and overbleached hair.

There is an increasing demand for the development of new hair protective products, and hair cosmetic industry is focused in alternative solutions such as proteins and protein-based materials. These can be incorporated in formulations of numerous topical applications because of their beneficial effects. Proteins can create a suitable environment for healthy hair because of their ability to bind water with the horny layer skin and its annexes. Proteins are included in the formulations as hair conditioning agents as they are capable to prevent the damage caused to the hair fibres based on their amphoteric and buffering properties $[4,5]$.

Keratin and silk fibroin were used in this work as base ingredients to prepare formulations for hair care cosmetic products. The effect of keratin hydrolysates on hair fibres was already described by many authors [6]. Keratin-based peptides increase the hydration, the brightness, the softness, the mechanical and the thermal properties of hair fibres [6]. Silk fibroin is non-toxic, biocompatible and shows an excellent water binding and absorbing capacity, which makes it also an excellent candidate to promote a moisturizing effect of hair formulations [7].

The aim of this study was the development of a new set of products for the protection and restoration of hair properties using keratin and silk fibroin as core ingredients. We evaluate the potential of keratin-based particles in the protection and strengthening of virgin and overbleached hair increasing the number of solutions available in hair care market. In this work, we have explored the keratin-based particles as hair restorative formulations rather than the respective bulk solutions, to take advantage of their physical characteristics. Furthermore, using protein-based particles instead of protein solutions and protein hydrolysates, we can explore in future the particles' ability to encapsulate fragrances and bioactive molecules.

The keratin-based particles were obtained by high pressure homogenization (HPH), and a full characterization of the formulations was observed in terms of size, stability, safety and their ability to improve and recover hairs' mechanical and thermal properties (Fig. 1).

\section{Experimental}

\section{Materials}

Natural Asian black human hair samples were provided by International Hair Importers \& Products Inc. (Glendale, New York, USA). The silk fibroin (SF) was extracted from Bombyx mori cocoons donated by Dr. Silvia Cappellozza from 'Sezione Specializzata per la Bachicoltura' (Padova). The DC (detergent compatible) protein assay kit was obtained from Bio-Rad, Portugal, and all other chemicals were supplied by Sigma-Aldrich, Spain.

\section{Extraction and purification of keratin}

Keratin was extracted from donated human hair obtained from a local barbershop. The hair samples were first washed according to the IAEA/RL/50 1978 recommendations to remove contaminants 
and lipids. The hair washing consisted of cycles of distilled water and acetone with continuous agitation. After washing, hair samples were kept at $40^{\circ} \mathrm{C}$ until completely dried.

The protocol for keratin extraction was adapted from Ayutthaya et al. [8], where a solution containing $8 \mathrm{M}$ urea, $0.2 \mathrm{M}$ SDS and $0.5 \mathrm{M}$ of sodium metabisulphite in a ratio of $10: 1$ (volume $(\mathrm{mL})$ of solution to mass (g) of dry hair) was used. The mixture was heated at $100^{\circ} \mathrm{C}$ for $30 \mathrm{~min}$ and then incubated overnight at $37^{\circ} \mathrm{C}$ with constant agitation. The extraction solution was then centrifuged at $2800 \mathrm{~g}$ for $10 \mathrm{~min}$, and the supernatant was filtered to remove hair fragments. The keratin solution was then dialysed for 5 days against distilled water using a dialysis membrane with a $14 \mathrm{kDa}$ cut-off. The water was renewed two times per day. After dialysis, the keratin solution was quantified by DC method according to the manufacturer's protocol [8].

\section{Extraction and purification of silk fibroin (SF)}

About $5 \mathrm{~g}$ of Bombyx mori cocoons was immersed in $1 \mathrm{~L}$ of boiling $\mathrm{Na}_{2} \mathrm{CO}_{3}(0.05 \mathrm{M})$ solution for $10 \mathrm{~min}$. The $\mathrm{Na}_{2} \mathrm{CO}_{3}$ solution was changed several times until the cocoons get fragmented. The degummed SF was then kept at $40^{\circ} \mathrm{C}$ until completely dried.

The degummed SF fibres were incubated in a solution of $9.3 \mathrm{M}$ lithium bromide at $60^{\circ} \mathrm{C}$ until total solubilization. The soluble SF was then filtered to remove undissolved fibres and dialysed for 5 days in distilled water using a dialysis membrane with a $14 \mathrm{kDa}$ cut-off. The water was changed two times per day. After dialysis, the SF solution was quantified by DC method according to the manufacturer's protocol.

\section{Synthesis of keratin-based particles}

Eight different formulations of keratin-based particles were produced by high pressure homogenization (HPH). The final particles were made-up within the following composition:

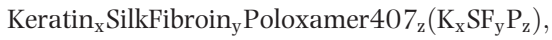

where $\mathrm{x}=80 \%, 90 \%, 95 \%$ and $100 \% ; \mathrm{y}=0 \%, 5 \%, 10 \%$ and $20 \% ; \mathrm{z}=0$ and $5 \mathrm{mg} \mathrm{mL}^{-1}$.

The protein solutions were prepared in phosphate buffer saline (PBS $1 \times$ ) pH 7.4 to a final concentration of $10 \mathrm{mg} \mathrm{mL}^{-1}$ with $0.5 \%$ $\left(\mathrm{v} \mathrm{v}^{-1}\right)$ of vegetable oil and poloxamer $407\left(\mathrm{Pol}_{407}\right)\left(5 \mathrm{mg} \mathrm{mL}^{-1}\right)$, when present. The homogenization process occurred at 240 580 bar during 10-13 $\mathrm{min}$ (3-5 $\mathrm{min}$ of open cycles and 7-8 min of close cycles) for each particle formulation. The emulsions obtained after homogenization cycles were centrifuged at $1792 \mathrm{~g}$ for $10 \mathrm{~min}$, at $4^{\circ} \mathrm{C}$, in Amicon tubes (Amicon Ultra-15 Millipore with a $100 \mathrm{kDa}$ cut-off) to separate the free protein from particles. The free protein was quantified by DC method, and the particle formation efficiency was estimated for each formulation using the formula:

Keratin-based particle formation $(\%)=\frac{[C]_{\mathrm{i}}-[\mathrm{C}]_{\mathrm{f}}}{[\mathrm{C}]_{\mathrm{i}}} \times 100$,

where $[C]_{\mathrm{i}}$ and $[\mathrm{C}]_{\mathrm{f}}$ are the initial and final concentrations of the protein in the aqueous solution, respectively. Each sample was assayed in triplicate.

In the current work, we used the keratin-based particles instead of the keratin and silk fibroin solutions, to take advantage of the particles' physical characteristics such as size and $\zeta$-potential. These properties could influence the particles' affinity to hair as well as their deposition pattern, which could render different degrees of improvement and restoration of human hair properties.

\section{Size, size distribution and surface charge characterization}

The emulsions were physicochemically analysed by means of size distribution and electrophoretic mobility ( $\zeta$-potential) at $\mathrm{pH} 7.4$ (PBS buffer) and $\mathrm{pH} 25^{\circ} \mathrm{C}$, by photon correlation spectroscopy and by electrophoretic laser Doppler anemometry, respectively, using dynamic light scattering in a Malvern Zetasizer NS. The values for viscosity and refractive index were taken as $0.890 \mathrm{cP}$ and 1.330 , respectively. Each sample was measured in triplicate, and results are presented as mean \pm standard deviation. Keratin-based particles were kept at $4^{\circ} \mathrm{C}$ and measured weekly until month 1 and then were measured monthly until month 3 .

Nanoparticle tracking analysis (NTA) was used to assess quantitatively the keratin-based particles. The experiments were performed using a NanoSight NS500 instrument (Salisbury, UK). This system includes a charge coupled device (CCD) camera that allows visualization and tracking the Brownian motion of laser-illuminated particles in suspension. The samples were ten times diluted with water and filtered (Millipore filters with pore size of $0.45 \mu \mathrm{m}$ ) and then injected into the system. The measurements were made at room temperature, and each video sequence was captured over $60 \mathrm{~s}$.

\section{Particle morphological characterization}

The morphology of particles was evaluated by STEM analysis. The diluted emulsions suspensions were dropped on copper grids with a 400 mesh carbon film, $3 \mathrm{~mm}$ in diameter. The shape and morphology of the microspheres were observed using a NOVA NanoSEM $200 \mathrm{FEI}$ instrument $(50000$ and $100000 \times$ ).

\section{Secondary structure analysis}

Infrared (FTIR) spectra were acquired at room temperature on a NICOLET-AVATAR 360 FTIR spectrometer using KBr discs made with 10 bar pressure. FTIR spectra were collected after 16 scans with a resolution of $32 \mathrm{~cm}^{-1}$ from 4000 to $600 \mathrm{~cm}^{-1}$. For protein, secondary structure Gaussian deconvolution of Amide I band region (wavenumber between 1600 and $1700 \mathrm{~cm}^{-1}$ ) was analysed using OriginPro 8.5 software (OriginLab Corporation, MA, USA).

In deconvolution analyses, a linear baseline was fitted; the number of components and their peak position were determined according to the second derivative spectrum of this same region, and the secondary structure content was calculated from the areas of the assigned peak as percentage fraction of the total area of the Amide I range. Using Gaussian function, all data were treated manually in three fitting modes: first, the baseline was held fixed and fitted, whereas intensity and bandwidth were allowed to vary; then, the baseline and bandwidth were fixed and fitted again, and finally, the baseline and centre peaks were fixed and fitted once more. The deconvoluted frequencies were then assigned to the respective secondary structure $\beta$-sheet, $\beta$-turns, random coil and $\alpha$-helix.

\section{Cellular viability assays}

\section{Cell culture maintenance}

The NCTC 2544 cell line (human skin keratinocytes) was cultured in DMEM, supplemented with $7.5 \% \mathrm{FBS}, 1 \%$ glutamine $(2 \mathrm{mM})$ 
and $1 \%\left(\mathrm{v} \mathrm{v}^{-1}\right)$ penicillin/streptomycin solution. Cells were maintained in $75-\mathrm{cm}^{2}$ tissue culture flasks at $37^{\circ} \mathrm{C}$ in a humidified atmosphere with $5 \% \mathrm{CO}^{2}$. The cell culture medium was renewed twice per week. For subcultures and plating, the adherent cells were detached with a trypsin solution $0.05 \%$.

Cell viability assessed by MTS assay

NCTC 2544 cells were seeded at a density of 22500 cells/well on a 48 -well tissue culture plate, the day before the experiments. The cells were then exposed to 6 concentrations $(0.01,0.05,0.1,0.25$, 0.5 and $1 \mathrm{mg} \mathrm{mL}^{-1}$ ) of keratin-based particles. Cells incubated with DMSO (30\% of the total volume) and cells without the addition of the compounds were used as controls: control of death and control of life, respectively.

After 24 and $48 \mathrm{~h}$ of contact, cell metabolic activity was assessed by MTS viability assay, following the manufacturer's standard protocol. The reduction in MTS by viable cells was measured with a 96-well plate reader at $490 \mathrm{~nm}$ in a microplate reader SpectraMax Plus (Molecular Devices).

Hair treatments

Black Asian Hair fibre samples $(0.1 \mathrm{~g})$ were washed before treatment with a classic commercial shampoo (Pantene). The hair samples were then subjected to eight cycles of bleaching $(8 \times \mathrm{B})$. Bleaching consisted on the application of $12 \% \mathrm{H}_{2} \mathrm{O}_{2}\left(\mathrm{v} \mathrm{v}^{-1}\right)$ in the presence of $0.1 \mathrm{M} \mathrm{Na}_{2} \mathrm{CO}_{3} / \mathrm{NaHCO}_{3}$, pH 9.0 buffer at $50^{\circ} \mathrm{C}$ for $1 \mathrm{~h}$, in a bath ratio of $1: 10$. Treatments were applied to the same tresses of hair. Hair samples (virgin and overbleached black Asian hair) were then subjected to the treatment with keratin-based particles. Treatments were performed for $1 \mathrm{~h}$ at $37^{\circ} \mathrm{C}$ with $0.5 \mathrm{mg} \mathrm{mL}^{-1}$ of particles in $0.05 \mathrm{M}$ phosphate buffer $\mathrm{pH}$ 7.5. Subsequently, all samples were thoroughly washed in tap water with a commercial shampoo and dried.

Scanning electron microscopy (SEM)

Hair fibres were randomly taken from the hair tress and mounted onto aluminium stubs using conductive carbon adhesive tape. Hair samples were coated with $80 \% \mathrm{Au}$ and $20 \%$ Pd before SEM (NOVA NanoSEM 200 FEI, Eindhoven, the Netherlands) observation at $5.0 \mathrm{kV}$.

\section{Hair fibre tensile test}

The effect of keratin-based particles on virgin and overbleached Asian hair was assessed by the differences in mechanical properties following the guidelines outlined in ASTM D1145-95 for fibre tensile testing. For this test, a set of hair fibres with low variability in diameter was selected using a light microscope.

The measurements were taken using a $250 \mathrm{~N}$ dynamometer Hounsfield machine. For each measurement, 30 single hair fibres were randomly taken from the tress. Each hair was individually mounted in the tensile jig by means of a paper template with a fixed gauge length of $20 \mathrm{~mm}$. Before the tensile test, the paper template was cut across. Measurements were taken under controlled conditions $\left(25 \pm 0.8^{\circ} \mathrm{C} ; \quad 70 \pm 5 \%\right.$ humidity) at a rate of $2.5 \mathrm{~mm} \mathrm{~min}^{-1}$ with $0.01 \mathrm{~N}$ preload force, and stretched until fibres broke. All measurements were made in the middle part of the hair fibre. Results were presented in Young's module $(\mathrm{mPa})$ and define the relationship between stress and strain, which is related to material strength and elasticity [9].
Table I Particle formation efficiency of keratin-based particles obtained by high pressure homogenization (HPH)

Particle formulation

Particle formation efficiency $(\%)$

$\begin{array}{ll}\mathrm{K}_{100} & 96.7 \pm 2.3 \\ \mathrm{~K}_{100} \mathrm{P} & 97.8 \pm 0.4 \\ \mathrm{~K}_{95} \mathrm{SF}_{5} & 91.0 \pm 1.1 \\ \mathrm{~K}_{95} \mathrm{SF}_{5} \mathrm{P} & 90.3 \pm 1.3 \\ \mathrm{~K}_{90} \mathrm{SF}_{10} & 95.2 \pm 3.4 \\ \mathrm{~K}_{90} \mathrm{SF}_{10} \mathrm{P} & 90.6 \pm 0.7 \\ \mathrm{~K}_{80} \mathrm{SF}_{20} & 92.6 \pm 2.6 \\ \mathrm{~K}_{80} \mathrm{SF}_{20} \mathrm{P} & 91.3 \pm 0.4\end{array}$

The values were calculated and expressed as mean $\pm \operatorname{SD}(n=3)$

Table II Size, polydispersity index (PDI) and $\zeta$-potential of keratin-based particles at the end of 3 months of storage at $4^{\circ} \mathrm{C}$

\begin{tabular}{llll}
\hline Formulation & Size $(\mathbf{n m})$ & PDI & $\zeta$-Potential $(\mathbf{m V})$ \\
\hline & & & \\
$\mathrm{K}_{100}$ & $210.2 \pm 2.4$ & $0.100 \pm 0.045$ & $-39.1 \pm 1.7$ \\
$\mathrm{~K}_{100} \mathrm{P}$ & $160.5 \pm 2.5$ & $0.266 \pm 0.007$ & $-22.0 \pm 1.0$ \\
$\mathrm{~K}_{95} \mathrm{SF}_{5}$ & $205.4 \pm 4.9$ & $0.167 \pm 0.008$ & $-42.9 \pm 0.6$ \\
$\mathrm{~K}_{95} \mathrm{SF}_{5} \mathrm{P}$ & $236.4 \pm 2.0$ & $0.267 \pm 0.006$ & $-11.3 \pm 1.2$ \\
$\mathrm{~K}_{90} \mathrm{SF}_{10}$ & $186.8 \pm 7.0$ & $0.154 \pm 0.007$ & $-39.4 \pm 0.4$ \\
$\mathrm{~K}_{90} \mathrm{SF}_{10} \mathrm{P}$ & $205.3 \pm 8.4$ & $0.218 \pm 0.015$ & $-9.0 \pm 1.8$ \\
$\mathrm{~K}_{80} \mathrm{SF}_{20}$ & $210.9 \pm 7.4$ & $0.135 \pm 0.022$ & $-35.0 \pm 1.2$ \\
$\mathrm{~K}_{80} \mathrm{SF}_{20} \mathrm{P}$ & $226.0 \pm 2.3$ & $0.212 \pm 0.020$ & $-9.50 \pm 1.4$ \\
& & & \\
\hline
\end{tabular}

The values were calculated and expressed as mean $\pm S D(n=3)$.

Differential scanning calorimetry

Thermal studies of the hair samples were conducted using a power compensated differential scanning calorimetry (DSC) instrument (DSC 6000, Perkin Elmer) and aluminium pans (max. pressure: $1 \mathrm{bar}$ ), at a temperature range from 50 to $250^{\circ} \Delta \mathrm{C}$ (heating rate: $5^{\circ} \Delta \mathrm{C} \mathrm{min}^{-1}$, sample weight: approximately $2 \mathrm{mg}$ ). The DSC device was calibrated using high-purity indium and zinc. Each test group was measured in triplicate, and mean values are reported.

\section{Assessment of feel assay}

A feel test with volunteers was performed to assess the effect of treatment using the keratin-based particles on the smoothness of virgin and overbleached Asian hair. The cohort included 30 volunteers from different ethnicities, 20 females and 10 males, with ages between 20 and 50 years. Two test series were performed, one with the virgin Asian hair and other with the overbleached Asian hair. A blind control (untreated hair) was included in each set of hair samples for the fidelity of the results. The feel test was performed as follows: the volunteer contacted first with the references (virgin and overbleached Asian hair without treatment) and then with the hair samples treated with the keratin-based particles and with the blind control, in a random order. The samples and the blind control were numbered to guarantee that volunteers did not have any information regarding sample's treatment. Afterwards, the volunteer was asked 


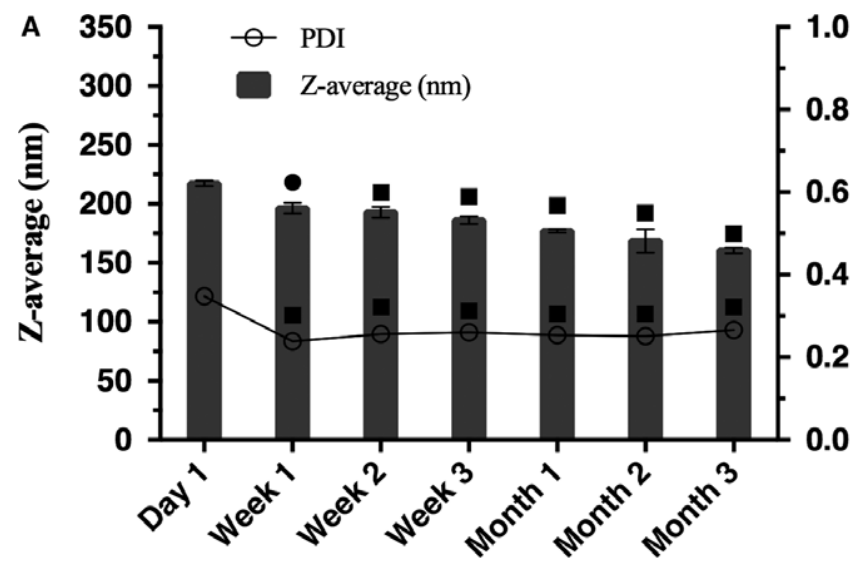

Time

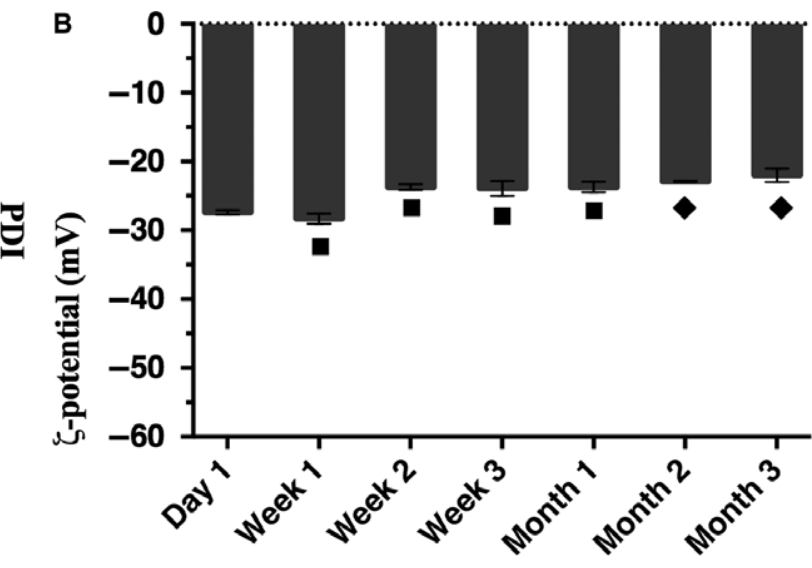

Time

Figure 2 Characterization of $\mathrm{K}_{100} \mathrm{P}$ in PBS, during storage at $4^{\circ} \mathrm{C}$ : (A) Z-average and polydispersity (PDI); (B) surface charge ( $\zeta$-potential). The data represent the mean \pm SD from three independent experiments. Data were analysed by one-way ANOVA: $P$-value $\leq 0.01 ; \bullet$-value $\leq 0.001$; $\square$-value $\leq 0.0001$, when compared to the results obtained at day 1 .


Figure 3 STEM micrographs (50 000 (A) and $100000 \times(\mathrm{B}))$ of $\mathrm{K}_{100} \mathrm{P}$ particles at day 1 after synthesis. to give a classification between 0 and 4 , where 0 corresponds to no increase in hair smoothness and 4 corresponds to a great improvement in hair smoothness.

\section{Statistical analysis}

Data are presented as average standard deviation (SD), $n=3$. Statistical comparisons were performed by one-way ANOVA with GraphPad Prism 5.0 software (La Jolla, CA, USA). Tukey's post-hoc test was used to compare all the results between them, and Dunnett's test was used to compare the results with a specific control. A $P$-value of $<0.05$ was considered to be statistically significant.

\section{Results and discussion}

\section{Particle formation efficiency}

After synthesis, the efficiency of keratin-based particle formation was determined by the quantification of free protein using DC method (Table I). The efficiency of particle formation ranged from $90.6 \%$ to $97.8 \%$, which clearly demonstrates the high capacity of keratin and silk fibroin to form particles during the HPH process.

\section{Particles physicochemical characterization}

Particle physical stability was evaluated over 3 months by measurements of size, PDI and $\zeta$-potential when stored at $4^{\circ} \mathrm{C}$. The physical characteristics of all formulations 3 months after synthesis are presented in Table II. Also, the physical stability over time of $\mathrm{K}_{100} \mathrm{P}$ is depicted in Fig. 2 . $\mathrm{K}_{100} \mathrm{P}$ corresponds to the formulation only with keratin and poloxamer 407 . The physical stability of the other keratin-based particles is present in Fig. S1.

All keratin-based particles presented a net negative surface $\zeta$-potential and a narrow size distribution with sizes ranging from 160 to $237 \mathrm{~nm}$ (Table II). Yet, considering composition and time, some statistical significant differences were identified. There was a relative decrease in particles size along time, going up to $26 \%$ for the $\mathrm{K}_{100} \mathrm{P}$ formulation. Regarding the $\zeta$-potential, there was a 
Table III Secondary structural assignments on keratin-based particles obtained by HPH

Secondary structure (\%)

Amide I deconvolution

B-Sheet $\quad$ B-Turn $\quad \alpha$-helix/random coil

\begin{tabular}{llll}
\hline Keratin control & 27 & 33.7 & 39.3 \\
Silk fibroin control & 28.2 & 39.2 & 32.6 \\
$\mathrm{~K}_{100}$ & 29 & 40.3 & 30.7 \\
$\mathrm{~K}_{100} \mathrm{P}$ & 31.0 & 38.4 & 29.6 \\
$\mathrm{~K}_{95} \mathrm{SF}_{5}$ & 34.8 & 39.2 & 25.9 \\
$\mathrm{~K}_{95} \mathrm{SF}_{5} \mathrm{P}$ & 30.8 & 42.7 & 26.4 \\
$\mathrm{~K}_{90} \mathrm{SF}_{10}$ & 32.4 & 41.8 & 25.8 \\
$\mathrm{~K}_{90} \mathrm{SF}_{10} \mathrm{P}$ & 30.1 & 39.6 & 30.0 \\
$\mathrm{~K}_{80} \mathrm{SF}_{20}$ & 33.4 & 39.4 & 27.2 \\
$\mathrm{~K}_{80} \mathrm{SF}_{20} \mathrm{P}$ & 34.2 & 38.7 & 27.1 \\
\end{tabular}

The results of Amide I deconvolution, expressed in percentages, were analysed using OriginPro 8.5 software.

variation from $-27.40 \mathrm{mV}$, at day 1 , to $-22.00 \mathrm{mV}$ after 3 months of storage at $4^{\circ} \mathrm{C}$ for this formulation. These changes in $\zeta$-potential could be associated with a reorganization of the proteins and $\mathrm{Pol}_{407}$ at particles' surface, leading to small alterations in the surface charge.

There was also a stabilization of the $\mathrm{K}_{100} \mathrm{P}$ particles at the end of the first week of storage, with a decrease in PDI value. The same trend was observed for the other keratin-based particles (data not shown). $\mathrm{Pol}_{407}$ is a surface active compound that, because of its amphiphilic structure, exhibits a tendency to accumulate at the interface between the aqueous and organic phase, lowering the surface tension and stabilizing the system [10]. This compound was used to control particle size, size distribution and shape, and to prevent aggregation and coalescence. Except for the $\mathrm{K}_{100} \mathrm{P}$ particles, there was an increase in size and PDI when the $\mathrm{Pol}_{407}$ was added to the formulations with keratin and silk fibroin. It was already described that $\mathrm{Pol}_{407}$ propylene oxide chains are not strong enough to be ideally absorbed in silk fibroin particles. Thus, the presence of this protein in the formulation could have influenced the effect of $\mathrm{Pol}_{407}$ on particle size and PDI [11].

Regarding the $\zeta$-potential, a change towards a less negative potential for all the particles was observed. These results were expected as the negative charge of the keratin side chains $\left(\mathrm{R}^{-} \mathrm{SO}_{3}{ }^{-}\right)$ was masked by the presence of $\mathrm{Pol}_{407}$ coating the particles, resulting in an increase in $\zeta$-potential to less negative values [12]. Despite the small changes observed regarding the particles' surface charge, the highly negatively charged formulations are considered as stable. The shape and the size of the keratin-based particles were also evaluated by STEM and NTA. Analysing STEM micrographs presented in Fig. 3, it was possible to verify the particles' spherical shape and the presence of a less dense layer surrounding the particles. This layer can be attributed to the presence of $\mathrm{Pol}_{407}$, which tends to accumulate in the interface between particles and water [10].

Using NTA, a size of $210 \mathrm{~nm}$ was observed for the $\mathrm{K}_{100} \mathrm{P}$ particles, taking into account $90 \%$ of population distribution (D90). These results were in agreement with the size determined by DLS at day 1 after particle synthesis.
The newly produced keratin-based particles presented size properties generally considered suitable for cosmetic applications [13].

\section{Effect of homogenization on the secondary structure of particles containing proteins}

To evaluate the extent of the emulsification effect on the secondary structure of keratin and silk fibroin, FTIR spectra of formulations were acquired.

To assess the type of secondary structures present, a deconvolution of Amide I (1600-1700 $\mathrm{cm}^{-1}$ ) region was performed and the results are presented in Table III. When the proteins were subjected to cycles of $\mathrm{HPH}$, some structural modifications were detected. Comparing the $K_{100}$ particles with the keratin solution, the $K_{100}$ particles showed higher absorbance for the analysed amides, which is related to the chemical bond concentration formed during the emulsification process (data not shown).

The variations of FTIR spectra could indicate conformational changes in the proteins and the achievement of complex particles. The results presented in Table III summarize the structural alterations on the proteins throughout the HPH process. The band assignment was performed according to Kong [14] where the deconvolution of Amide I allowed to analyse the corresponding structural assignments. A component centred between approximately 1658 and $1650 \mathrm{~cm}^{-1}$ was assigned to $\alpha$-helix structures. Bands in the regions of $1640-1620 \mathrm{~cm}^{-1}$ and $1695-1690 \mathrm{~cm}^{-1}$ were assigned to $\beta$-sheet, and bands flanked by 1680 and $1660 \mathrm{~cm}^{-1}$ were assigned to $\beta$-turns [14].

Comparing the values before and after the application of HPH to produce the particles, an increase in the percentage of $\beta$-strands (sheets and turns) was observed. Concomitantly, there was a reduction in the percentage of $\alpha$-helix/random coil structures. The increase in $\beta$-strands was related to the HPH emulsification process, which contributes to an increase in protein's crystallinity, mostly because of the formation of $\beta$-strand structures [15-17]. The incorporation of silk fibroin on particles formulation contributed to an increase in the percentage of $\beta$-sheets $[18,19]$. Silk fibroin selfassembly process is predominantly composed by this conformation, which increases encapsulation efficiency and enables control of drug release kinetics [19-21]. When compared with the $\mathrm{K}_{100}$ particles, the addition of silk fibroin and poloxamer 407 to the formulations led to a reduction in absorbance on the regions corresponding to the Amides I, II and III (data not shown). These changes evidence the chemical modifications of the formulations observed by addition of other components.

In Table III is patent the effect of silk fibroin and $\mathrm{Pol}_{407}$ on particle conformation triggering the formation of $\beta$-strands, in special $\beta$ turn, during the HPH process. An increase in these conformations may contribute to more stable particles because $\beta$-sheets are envisioned with reverse $\beta$-turns conferring stability and the possibility to connect with other $\beta$-sheets, improving particle resistance and rigidity [20, 21].

\section{In vitro evaluation of keratin-based particle potential cytotoxicity}

When developing new products that will contact with human skin, it is crucial to understand whether those products will potentially display any type of cytotoxicity. Ultimately, the development of new cosmetic products relays on product safety when applied to humans. The use of cell lines is well established for the evaluation of the potential cytotoxicity of cosmetic products $[22,23]$. Also, in 



Figure 4 Relative viability of NCTC-2544 human keratinocytes (evaluated by the MTS assay) after $48 \mathrm{~h}$ incubation with 0.01 , 0.05 , 0.1 , 0.25 , 0.5 and $1 \mathrm{mg} \mathrm{mL} \mathrm{mL}^{-1}$ of $\mathrm{K}_{100}$ and $\mathrm{K}_{100} \mathrm{P}(\mathrm{A}), \mathrm{K}_{95} \mathrm{SF}_{5}$ and $\mathrm{K}_{95} \mathrm{SF}_{5} \mathrm{P}(\mathrm{B}), \mathrm{K}_{90} \mathrm{SF}_{10}$ and $\mathrm{K}_{90} \mathrm{SF}_{10} \mathrm{P}(\mathrm{C}), \mathrm{K}_{80} \mathrm{SF}_{20}$ and $\mathrm{K}_{80} \mathrm{SF}_{20} \mathrm{P}$ (D) particles. Cells incubated with culture medium only were used as life control (+) and cells incubated with 30\% DMSO as death control ( - ). Data were calculated in relation to the life control (100\%). Results are the mean \pm SD of triplicates of three independent experiments.

the European Union there are provisions prohibiting animal testing of cosmetic products and well established that animal experiments must be replaced by alternative methods that are scientifically accepted. Human keratinocytes were chosen as the keratin-based particles will be applied on hair and would therefore come into contact with the hair scalp and eventually be adsorbed through it. More specifically, the NCTC-2544 keratinocyte cell line was selected to evaluate the potential cytotoxic effect of keratin-based particles as this cell line is already a reliable method to prevent animal skin tests for cytotoxicity studies and contact of potential allergens $[22,23]$.

The effect of keratin-based particles on the cellular metabolic activity of human keratinocytes, as a means to predict cytotoxicity, was evaluated by the MTS assay. The data on viability of cells after $48 \mathrm{~h}$ of incubation with the keratin-based particles are presented in Fig. 4. The cytotoxic effect of the individual components of the particles (keratin, silk fibroin and $\mathrm{Pol}_{407}$ ) was initially evaluated, and no signs of cell toxicity were verified for any of the tested concentrations and time points (data not shown). The same tendency was verified when cells were exposed to increasing concentrations of keratin-based particles.

The lowest viability was observed for the highest concentration of $\mathrm{K}_{80} \mathrm{SF}_{20} \mathrm{P}$ particles $(94.1 \pm 31.1 \%)$, which still was not significantly different from the life control. For some particle concentrations $\left(\mathrm{K}_{100}\right.$ [0.05], $\mathrm{K}_{100} \mathrm{P}$ [0.1], $\mathrm{K}_{95} \mathrm{SF}_{5}$ [0.1], $\mathrm{K}_{95} \mathrm{SF}_{5} \mathrm{P}$ [0.5], $\mathrm{K}_{90} \mathrm{SF}_{10}$ [0.5] and $\mathrm{K}_{80} \mathrm{SF}_{20}$ [0.5]), there was a pro-proliferative effect of the keratin-based particles. This keratin-based material effect, such as hydrogels, scaffolds and films, was already described in cell adhesion and proliferation studies [24, 25]. The uniformity of the viability results after $48 \mathrm{~h}$ of incubation and comparing with the $24 \mathrm{~h}$ incubation (data not shown) shows the ability of the keratinocytes to adapt to the presence of the keratin-based particles, which argues for the safety of these particles. Furthermore, the addition of $\mathrm{Pol}_{407}$ and silk fibroin to the formulation did not significantly affect the viability of keratinocytes.

\section{Hair treatment with keratin-based particles}

After confirmation of the keratin-based particles safety in human keratinocytes, virgin and overbleached $(8 \times \mathrm{B})$ Asian hairs were incubated with $0.5 \mathrm{mg} \mathrm{mL}^{-1}$ of each formulation for $1 \mathrm{~h}$. This concentration was selected considering the particles' cytotoxicity profiling. Although no significant cytotoxic effect was verified for any of the tested concentrations after $48 \mathrm{~h}$ of exposition, $0.5 \mathrm{mg} \mathrm{mL}^{-1}$ of particles was the highest concentration where no decrease in cellular viability was noted for any of the keratin-based particles tested.

When developing new formulations for hair care, it is important to evaluate the ability of their components to bind hair. After the hair treatment, roughly bound keratin-based particles were washed off and the remaining tightly bound particles (on the hair surface and/or in the cortex) were visualized by SEM (Fig. 5).

Analysing Fig. 5, the effect of the bleaching process on the appearance and structure of hair is notorious. Although the virgin hair (Fig. 5A) shows a natural appearance and displays a scale structure with smooth edges, the overbleached hair (Fig. 5C) 



Figure 5 SEM micrographs $(10000 \times$ magnification) of Asian virgin hair (A), Asian virgin hair treated with $\mathrm{K}_{80} \mathrm{SF}_{20} \mathrm{P}$ particles (B), Asian overbleached hair $(C)$ and Asian overbleached hair treated with $\mathrm{K}_{80} \mathrm{SF}_{20} \mathrm{P}$ particles (D). Particles are highlighted by arrows.
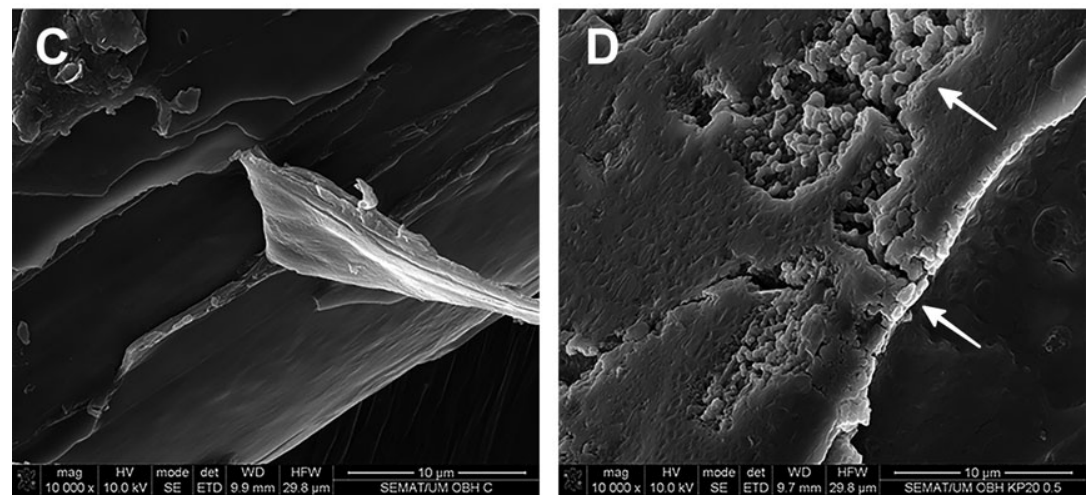

Table IV Improvement ( $\mathrm{I} \%)$ and recovery $(\mathrm{R} \%)$ of hair mechanical properties measured in terms of Young modulus and tensile strength (\%) after treatment with keratin-based particles, compared with untreated virgin hair and untreated overbleached hair

\begin{tabular}{|c|c|c|c|c|}
\hline \multirow[b]{2}{*}{ Formulation } & \multicolumn{2}{|l|}{ Young modulus } & \multicolumn{2}{|l|}{ Tensile strength } \\
\hline & Virgin hair (\%l) & Overbleached hair $(\% R+I)$ & Virgin hair (\%l) & Overbleached hair $(\% \mathbf{R}+1)$ \\
\hline $\mathrm{K}_{100}$ & 14.24 & 23.26 & 6.92 & 14.91 \\
\hline $\mathrm{K}_{100} \mathrm{P}$ & 23.85 & 28.58 & 9.02 & 7.75 \\
\hline $\mathrm{K}_{95} \mathrm{SF}_{5}$ & 17.37 & 23.31 & 12.58 & 9.22 \\
\hline $\mathrm{K}_{95} \mathrm{SF}_{5} \mathrm{P}$ & 16.45 & 23.68 & 11.13 & 14.14 \\
\hline $\mathrm{K}_{90} \mathrm{SF}_{10}$ & 28.94 & 30.74 & 11.98 & 22.68 \\
\hline $\mathrm{K}_{90} \mathrm{SF}_{10} \mathrm{P}$ & 27.08 & 36.31 & 13.75 & 16.77 \\
\hline $\mathrm{K}_{80} \mathrm{SF}_{20}$ & 31.94 & 28.82 & 23.07 & 20.17 \\
\hline $\mathrm{K}_{80} \mathrm{SF}_{20} \mathrm{P}$ & 41.84 & 36.14 & 27.74 & 19.34 \\
\hline
\end{tabular}

showed signs of scale erosion and hair degradation, which contributed for the weakening of the hair fibre [26].

The deposition of the keratin-based particles on the hair fibres was evident when comparing the micrographs of treated and untreated hair. The deposition and distribution were dependent on the particle formulation (data not shown) and type of hair used (virgin vs overbleached). In Figs 5B (treated virgin hair) and 4D (treated overbleached) is presented the binding of $\mathrm{K}_{80} \mathrm{SF}_{20} \mathrm{P}$ particles to hair.

This formulation was able to recover and improve hair mechanical properties to a great extent compared with the other formulations (Table IV), and thus, its data are presented here. In the treated virgin hair (Fig. $5 \mathrm{~B}$ ), the $\mathrm{K}_{80} \mathrm{SF}_{20} \mathrm{P}$ particles tend to be distributed along the hair fibre with a preferential deposition in the interlayer zone of the cuticles. This behaviour is similar to that observed with the hair conditioners. It was already described by many authors that the conditioner tends to accumulate in the area surrounding the cuticle scale edges, filling the damaged area of the cuticles, making it possible to physically 'repair' some damages in the hair fibre [27, 28].

For the treated overbleached hair (Fig. 5D), the $\mathrm{K}_{80} \mathrm{SF}_{20} \mathrm{P}$ particles are evenly distributed along the hair fibre with a tendency to 

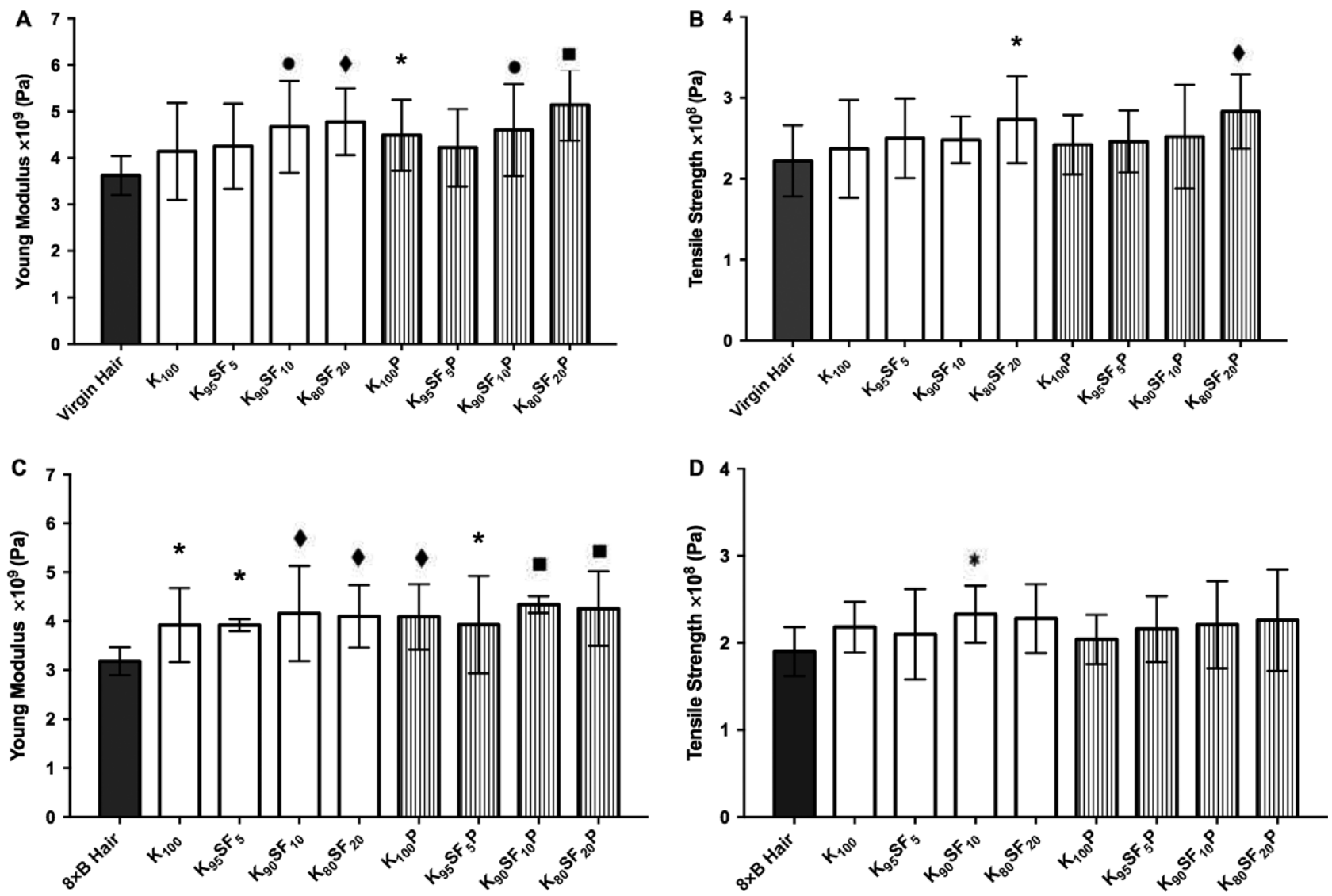

Figure 6 Mechanical resistance parameters: (A) and (C) Young modulus and (B) and (D) tensile strength of virgin and overbleached Asian hair ( $8 \times B)$ before and after treatment with $0.5 \mathrm{mg} \mathrm{mL}{ }^{-1}$ of keratin-based particles. Values are the mean \pm SD of twenty independent measurements. Statistical significant differences from the control ((A) and (B): untreated virgin air; (C) and (D): overbleached hair $(8 \times))$ are indicated as: * $P$-value $\leq 0.05$, $P$-value $\leq 0.01$; $P$-value $\leq 0.001 ; \mathbf{\square}$-value $\leq 0.0001$.

Table V Keratin $\alpha$-helix denaturation enthalpies of virgin and overbleached Asian hair after treatment with $0.5 \mathrm{mg} \mathrm{mL}^{-1}$ of keratin-based particles

\begin{tabular}{lll}
\hline $\begin{array}{l}\text { Keratin-based } \\
\text { particles }\end{array}$ & $\begin{array}{l}\text { DeltaH } \mathbf{(} \mathbf{J ~ g}^{-\mathbf{1}} \text { ) } \\
\text { (virgin hair) }\end{array}$ & $\begin{array}{l}\text { DeltaH } \mathbf{(} \mathbf{J ~ g}^{-\mathbf{1}} \text { ) } \\
\text { (overbleached hair) }\end{array}$ \\
\hline $\mathrm{K}_{100}$ & \\
$\mathrm{~K}_{100} \mathrm{P}$ & $2.18 \pm 0.60$ & $2.36 \pm 0.97$ \\
$\mathrm{~K}_{95} \mathrm{SF}_{5}$ & $1.81 \pm 0.19$ & $1.85 \pm 0.26$ \\
$\mathrm{~K}_{95} \mathrm{SF}_{5} \mathrm{P}$ & $3.54 \pm 1.32$ & $1.51 \pm 0.50$ \\
$\mathrm{~K}_{90} \mathrm{SF}_{10}$ & $4.23 \pm 0.16$ & $3.77 \pm 1.75$ \\
$\mathrm{~K}_{90} \mathrm{SF}_{10} \mathrm{P}$ & $4.61 \pm 0.69$ & $2.15 \pm 0.95$ \\
$\mathrm{~K}_{80} \mathrm{SF}_{20}$ & $3.87 \pm 1.38$ & $2.58 \pm 1.59$ \\
$\mathrm{~K}_{80} \mathrm{SF}_{20} \mathrm{P}$ & $3.01 \pm 1.28$ & $2.29 \pm 0.21$ \\
& $3.43 \pm 0.92$ & $1.54 \pm 0.28$ \\
\hline
\end{tabular}

The values were calculated and expressed as the energy increase between the samples treated with particles and the respective control: virgin or overbleached hair $(n=3)$.

form film-like structures over the damaged hair. The differences observed on the deposition pattern could be directly related to the overbleaching process, which affected the cuticle structure and the surface chemistry. The appearance of cystic acid termination $\mathrm{SO}_{3}{ }^{-}$ after bleaching resulted in an increase in the net negative charge and surface hydrophilicity of overbleached hair improving the electric attraction to keratin-based particles [29]. The formation of a film-like deposition in the $\mathrm{K}_{80} \mathrm{SF}_{20} \mathrm{P}$ particles on the overbleached hair resulted from a stronger interaction between the particles and the hair fibre.

Recovery of the mechanical and thermal properties of virgin and overbleached Asian hair

To evaluate the extent to which the particles contribute to the mechanical strength and thermal properties of virgin and overbleach hair, we performed the determination of the mechanical resistance of hair samples. Hair resistance was determined using the calculated Young's modulus (stiffness), and tensile strength of virgin and overbleached Asian hair was determined before and after treatment with $0.5 \mathrm{mg} \mathrm{mL}^{-1}$ of keratin-based particles (Fig. 6).

The repeated chemical bleaching treatments affect the appearance and structure of hair, which results in the loss of hair resistance. The overbleaching of Asian black hair induced a loss of stiffness in about $14 \%$ and a loss of tensile strength in about $17 \%$. 

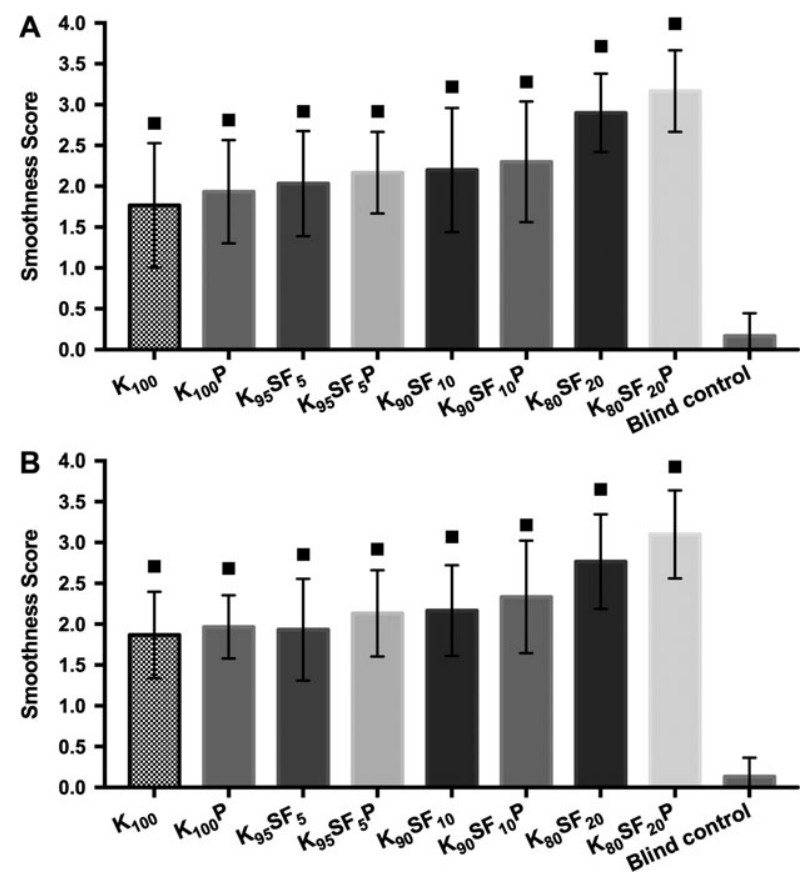

Figure 7 Increase in virgin hair (A) and overbleached hair (B) smoothness after treatment with the keratin-based particles. The qualitative score data were obtained from a cohort of 30 volunteers. Score $0-$ no improvement in smoothness; 1 - slight improvement in smoothness; 2 - improvement in smoothness; 3 -good improvement in smoothness; 4 - great improvement in smoothness. The data represent the mean \pm SD from the thirty volunteers. Data were analysed by one-way ANOVA: $\quad P$-value $\leq 0.0001$, when compared to the results of the blind control (untreated hair).

Analysing Fig. 6, it was possible to observe that the application of the keratin-based particles resulted in the recovery (R) and even improvement (I) of overbleached hair mechanical properties to values higher than what was measured for the control (untreated overbleached hair). Regarding virgin hair, all the keratin-based particles were able to improve (I) its mechanical properties. The treatment of overbleached and virgin hair with buffer did not show any significant recovery of the mechanical properties (data not shown), thus attesting the beneficial role of the keratin-based particles.

The Young modulus analysis indicated that the particles with higher percentage of silk fibroin $(10 \%$ and $20 \%)$ significantly improve the stiffness of both virgin and overbleached hair. An increase in tensile strength with increasing percentages of silk fibroin was only significant for $\mathrm{K}_{80} \mathrm{SF}_{20}$ and $\mathrm{K}_{80} \mathrm{SF}_{20} \mathrm{P}$ formulations, which improve the tensile strength of virgin hair in $23.07 \%$ and $27.74 \%$ (Table IV), respectively. The tensile strength of overbleached hair was significantly increased by $22.69 \%$ after the application of $\mathrm{K}_{90} \mathrm{SF}_{10}$ particles (Table IV).

Comparing all particle formulations (Table IV), the best formulation in terms of Young's modulus was the $\mathrm{K}_{80} \mathrm{SF}_{20} \mathrm{P}$, which led to an improvement up to $41.85 \%$ and $36.14 \%$ for the virgin and overbleached hair, respectively.

The improvement and recovery of hair's mechanical properties could be directly related to the number and distribution of particles attached to the hair surface. Hair samples with more particles on their surface had the highest and more statistically significant values for Young's modulus. Despite this positive correlation between amount of particles on the hair surface and the improvement of its mechanical properties, the increase in Young's modulus could also be related to the ability of the keratin-based particles to penetrate into the hair cortex, contributing to the stabilization of keratin's $\alpha$ helix, giving this structure a higher resistance to unfold during stretching.

Particle composition also influenced the improvement of hair's mechanical properties. Generally, there was an increase in Young's modulus values with increasing amounts of silk fibroin in the formulation. Such observation could be related to the secondary structure of silk fibroin. This protein is rich in $\beta$-strands, which are associated with higher resistance and stiffness profiles [20, 30] while combining tensile strength and toughness [31].

The study of the effect of hair care products on hair's mechanical and thermal properties is essential when developing new formulations. Therefore, DSC measurements were taken to assess whether keratin-based particles penetrate into the hair cortex and whether they protect hair from thermal denaturation. One important parameter analysed by this technique is the $\alpha$ helix keratin denaturation, which is identified by a peak with a temperature between 210 and $250^{\circ} \mathrm{C}$ [32]. The peak observed at $221.9^{\circ} \mathrm{C}$ for the lyophilized keratin in Figs S2B and S3B is within this temperature range. Peaks around this temperature range were selected to evaluate the effect of the keratin-based particles treatment on the enthalpies values for virgin and overbleached Asian hair. If there is an increase in the enthalpy of $\alpha$-helix keratin denaturation, the formulation is somehow interacting and stabilizing the keratin structure, protecting it from damage [33]. The thermograms of virgin Asian hair, overbleached Asian hair, lyophilized keratin and of hair samples treated with the keratin-based particles are shown in Figs S2 and S3.

Table $\mathrm{V}$ shows the enthalpy values for the $\alpha$-helix keratin denaturation. The enthalpies values correspond to the difference between the virgin and overbleached hair treated with the keratin-based particles and the hair without treatment.

The treatment of hair with the particles resulted in an increase in the value of $\alpha$-helix denaturation enthalpies. For the virgin hair, the best formulations were the $\mathrm{K}_{80} \mathrm{SF}_{20}$ and $\mathrm{K}_{100} \mathrm{P}$, whereas for the overbleached hair, the best formulations were the $\mathrm{K}_{80} \mathrm{SF}_{20}$ and $\mathrm{K}_{95} \mathrm{SF}_{5} \mathrm{P}$. It was already demonstrated by some studies that silk fibroin tends to establish intermolecular interactions with keratin, so it was expected that formulations with it would have higher denaturation enthalpies [15]. These results corroborate the positive effect of keratin-based particles on the mechanical and thermal properties of virgin and overbleached hair.

\section{Effect of keratin-based particles on hair smoothness}

The effect of a formulation on hair smoothness is an essential parameter during the development of new hair cosmetic products. End-users prefer products, which turns hair softer to the touch over a product that does not increases hair smoothness. A subjective assessment with a cohort of 30 volunteers was performed to study whether the treatment of virgin and overbleached with the keratinbased particles increases hair smoothness - Fig. 7. Analysing Fig. 7, it demonstrated the ability of all keratin-based formulations to improve hair's smoothness, with a direct relation with the increase in silk fibroin concentration in the formulation. This 
improvement in hair texture could be related to the moisturizer effect of silk fibroin, capacity already demonstrated and proved for other formulations applied on skin [7]. Besides, the accumulation of the keratin-based particles on the cuticles edges (Fig. 5B) or their ability to form film-like structures (Fig. 5D) attenuated the hair surface irregularities increasing hair smoothness. This behaviour was similar to the described for hair conditioners [34].

\section{Conclusions}

The conventional chemical treatments used in hair cosmetic have detrimental effects on the mechanical and thermal properties of hair. The development of formulations capable of recovering and improving the properties of hair is mandatory. In the present study, keratin-based particles were successfully produced by $\mathrm{HPH}$ and applied to virgin and chemically overbleached hair. Generally, the particles were very stable over time and proved to be safe when tested in human keratinocytes. Depending on hair cuticle structure, hair surface chemistry and particle formulation, the keratin-based particles exhibited different deposition patterns on hair's surface. All the formulations were able to induce significant recovery of the stiffness and tensile strength of virgin and overbleached hair along with an increase in the $\alpha$-helix denaturation enthalpy and of surface smoothness for both types of hair.

The keratin-based particles here presented are excellent candidates as new restorative hair care products, opening new perspectives on the use of functional particle-based formulations in hair cosmetic industry. Additionally, these particles will be further explored to encapsulate fragrances and bioactive molecules, which will result in a set of multifunctional keratin-based formulations for hair restoration, hair targeting and hair beauty.

\section{Acknowledgements}

This study was supported by FCT under the scope of the strategic funding of UID/BIO/04469/2013 unit and COMPETE2020 (POCI01-0145-FEDER-006684) and BioTecNorte operation (NORTE-010145-FEDER-000004) and Nanotechnology Based Functional Solutions (NORTE-01-0145- FEDER-000019) funded by the European Regional Development Fund under the scope of Norte2020 - Programa Operacional Regional do Norte. We also acknowledge the strategic programme UID/BIA/04050/2013 (POCI-01-0145-FEDER007569) funded by national funds through Fundação para a Ciência e a Tecnologia (FCT) and by the ERDF through the COMPETE2020 Programa Operacional Competitividade e Internacionalização (POCI). Artur Ribeiro and Ana Tinoco thank FCT for funding the scholarships with the references SFRH/BPD/98388/2013 and SFRH/BD/ $114035 / 2015$, respectively.

\section{Conflict of interest}

There are no conflict of interests to declare.

\section{References}

1. Harrison, S. and Sinclair, R. Hair colouring, permanent styling and hair structure. J. Cosmet. Dermatol. 2, 180-185 (2003).

2. Ribeiro, A., Matamá, T., Cruz, C.F., Gomes, A.C. and Cavaco-Paulo, A.M. Potential of human $\gamma \mathrm{D}$-crystallin for hair damage repair: insights into the mechanical properties and biocompatibility. Int. J. Cosmet. Sci. 35 , 458-466 (2013)

3. Miranda, R., Santana, T. and Simone, B. Thermal analysis of hair treated with oxidative hair dye under influence of conditioners agents. J. Therm. Anal. Calorim. 106, 399405 (2011).

4. Secchi, G. Role of protein in cosmetics. Clin. Dermatol. 26, 321-325 (2008).

5. Gavazzoni Dias, M.F. Hair cosmetics: an overview. Int. J. Trichol. 7, 2 (2015).

6. Villa, A.L.V., Aragão, M.R.S., dos Santos, E.P., Mazotto, A.M., Zingali, R.B., De Souza, E.P. and Vermelho, A.B. Feather keratin hydrolysates obtained from microbial keratinases : effect on hair fiber. BMC Biotechnol. 13, 15-25 (2013).

7. Daithankar, A.V., Padamwar, M.N., Pisal, S.S., Paradkar, A.R. and Mahadik, K.R. Moisturizing efficiency of silk protein hydrolysate : Silk fibroin. Indian J. Biotechnol. 4, 115-121 (2005).

8. Isarankura Na Ayutthaya, S., Tanpichai, S. and Wootthikanokkhan, J. Keratin extracted from chicken feather waste: extraction, preparation, and structural characterization of the keratin and keratin/biopolymer films and electrospuns. J. Polym. Environ. 23, 506-516 (2015).

9. Askeland, D.R., Fulay, P.P. and Wright, W.J. The Science and Engineering of Materials, 6th edn. Cengage Learning, Boston (2010).

10. Loureiro, A., Nogueira, E., Azoria, N.G. et al. Size controlled protein nanoemulsions for active targeting of folate receptor positive cells. Colloids Surf. B Biointerfaces 135, 90-98 (2015).

11. Tadros, T. F. (2007) Colloid Aspects of Cosmetic Formulations with Particular Reference to Polymeric Surfactants. In: Colloid Stab. pp 1-34 WILEY-VCH Verlag $\mathrm{GmbH}$ \& Co. KGaA, Weinheim (2007).

12. Devi, D.R., Sandhya, P. and Hari, B.N.V. Poloxamer: a novel functional molecule for drug delivery and gene therapy. J. Pharm. Sci. Res. 5, 159-165 (2013).

13. Rosen, J., Landriscina, A. and Friedman, A.J. Nanotechnology-based cosmetics for hair care. Cosmetics 2, 211-224 (2015).

14. Kong, J. and Yu, S. Fourier transform infrared spectroscopic analysis of protein secondary structures. Acta Biochim. Biophys. Sin. (Shanghai) 39, 549-559 (2007).

15. Vasconcelos, A., Freddi, G. and Cavaco-Paulo, A. (2008) Biodegradable Materials Based on Silk Fibroin and Keratin. 1299-1305
16. Lovelyn, C. and Attama, A.A. Current state of nanoemulsions in drug delivery. J. Biomater. Nanobiotechnol. 2, 626-639 (2011).

17. Rabotyagova, O.S., Cebe, P. and Kaplan, D.L. Role of polyalanine domains in bMacromol. Biosci. 10, 49-59 (2010).

18. Zhao, Z., Chen, A. and Li, Y. Fabrication of silk fibroin nanoparticles for controlled drug delivery. J. Nanopart. Res. 14, 736 (2012).

19. Tudora, M.-R., Zaharia, C., Stancu, I.-C., Vasile, E., Truşcă, R. and Cincu, C. Natural Silk Fibroin Micro- and Nanoparticles with potential uses in Drug Delivery Systems. UPB Sci. Bull. Ser. B 75, 43-52 (2013).

20. Perticaroli, S., Nickels, J.D., Ehlers, G. and Sokolov, A.P. Rigidity, secondary structure, and the Universality of the Boson peak in proteins. Biophys. J . 106, 2667-2674 (2014).

21. Vollrath, F. and Knight, D.P. Liquid crystalline spinning of spider silk. Nature $\mathbf{4 1 0}$, 541-548 (2001).

22. Romano, P., Manniello, A., Aresu, O., Armento, M., Cesaro, M. and Parodi, B. Cell Line Data Base : structure and recent improvements towards molecular authentication of human cell lines. Nucleic Acids Res. 37, 925-932 (2009).

23. Corsini, E., Galbiati, V., Galli, C.L. and Marinovich, M. NCTC 2544 and IL-18 production : a tool for the identification of contact allergens. Toxicol. Vitr. 27, 1127-1134 (2013). 
24. Rouse, J.G. and Van Dyke, M.E. A review of keratin-based biomaterials for biomedical applications. Materials (Basel) 3, 999-1014 (2010).

25. Sierpinski, P., Garrett, J., Ma, J. et al. The use of keratin biomaterials derived from human hair for the promotion of rapid regeneration of peripheral nerves. Biomaterials 29, 118-128 (2008).

26. Robinson, V. A study of damaged hair. J. Soc. Cosmet. Chem. 27, 155-161 (1976).

27. Bhushan, B. Nanoscale characterization of human hair and hair conditioners. Prog. Mater Sci. 53, 585-710 (2008).
28. Latorre, C. and Bhushan, B. Nanotribological effects of hair care products and environment on human hair using atomic force microscopy. J. Vac. Sci. Technol., A $\mathbf{2 3}$, 1034-1045 (2005).

29. Wolfram, L.J., Ph, D., Hall, K., Sc, B., Hui, I. and Sc, M. The mechanism of hair bleaching. J. Soc. Cosmet. Chem. 900, 875-900 (1970).

30. Wray, L.S., Hu, X., Gallego, J., Georgakoudi, I., Omenetto, F.G., Schmidt, D. and Kaplan, D.L. Effect of processing on silk-based biomaterials: reproducibility and biocompatibility. J. Biomed. Mater. Res. B Appl. Biomater. 99, 89-101 (2011).
31. Hu, X., Cebe, P., Weiss, A.S., Omenetto, F. and Kaplan, D.L. Protein-based composite materials. Mater. Today 15, 209-215 (2012).

32. Monteiro, V.F., Maciel, A.P. and Longo, E. Thermal analysis of caucasian human hair. J. Therm. Anal. Calorim. 79, 289-293 (2005).

33. Wortmann, F. and Deutz, H. Thermal analysis of ortho- and para-cortical cells isolated from wool fibers. J. Appl. Polym. Sci. 68, 1991-1995 (1998).

34. Wei, G., Bhushan, B. and Torgerson, P.M. Nanomechanical characterization of human hair using nanoindentation and SEM. Ultramicroscopy 105, 248-266 (2005).

\section{Supporting Information}

Additional Supporting Information may be found online in the Supporting Information section at the end of the article:

Figure S1. Characterization of Keratin-based particles in PBS, during storage at $4^{\circ} \mathrm{C}$.

Figure S2. DSC thermograms of virgin Asian hair (A), lyophilized keratin (B) and virgin Asian hair after treatment with the keratinbased particles.

Figure S3. DSC thermograms of overbleached Asian hair (A), lyophilized keratin (B) and overbleached Asian hair after treatment with the keratin-based particles. 